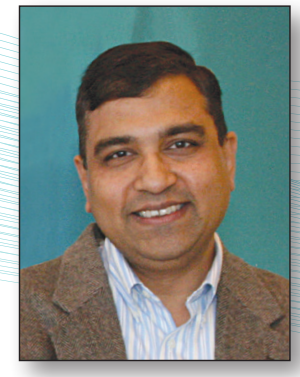

Gopal R. Rao

Editor, MRS Bulletin

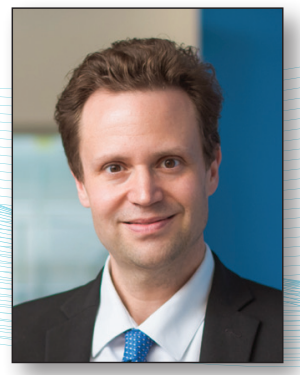

Markus J. Buehler

Impact Editor, MRS Bulletin

\title{
New horizons for MRS Bulletin
}

$\mathrm{T}$ he MRS Bulletin starts its 45th year of publication this year. As the flagship publication of the Materials Research Society (MRS), it has gone through several iterations and changes, starting as a simple newsletter to the present version with monthly theme topics, research news, popular features, and a strong and dynamic online presence. The content has evolved over time, as it should, and the Bulletin plays the dual role of a scientific journal with overview articles as well as a society magazine for MRS.

MRS Bulletin has had a significant impact on the materials and MRS communities during its history. It has enjoyed a healthy journal impact factor in the 4 to 6 range over many years, with the current (2018) impact factor being 4.655 and a 5-year impact factor of 5.408. Its influence on the materials research community, however, goes well beyond these numbers, as many readers of the Bulletin and colleagues tell us. The MRS Bulletin brand represents quality, and a lot of work goes into developing content as well as into the production process. With a committed Editorial Board and dedicated volunteer volume organizers, guest editors, authors, and staff, much has been accomplished, and we look back with satisfaction at all that has been achieved.

But there has always been the thought that we could do more and better. A task force instituted in 2018 explored this and came up with several recommendations, the major one of which was the establishment of a new section publishing select, high-quality original research. As you may have heard, we recently announced a new MRS Bulletin Impact section with Markus Buehler as the editor.

The Bulletin Impact section will be a premier outlet for high-profile original materials research. It will include a premium selection of new, original, and important research that demonstrates a significant impact or advance of scientific understanding of exceptional interest to the materials research community. We seek to publish the most innovative materials research work that will capture the minds and attention of researchers around the world and provide fundamental insights in all fields of materials research and related disciplines. We will publish papers that identify emerging hot topics and trends and pursue articles in these areas that will have a lasting and deep influence. A selection of original research papers will be accompanied by opinion and perspective articles to offer context to the results reported. Select papers will also be highlighted via news releases and other means of dissemination, such as video and social media.

Building on the strong reputation and history of the Bulletin, the Impact section will offer authors high visibility, rigorous peer review, rapid publication, access to a broad readership, and high standards of editing and production. The accompaniment of high-quality illustrations and figures will add to the distinction of these papers.

MRS leadership, staff, and volunteers are all incredibly excited about this new opportunity for MRS and for materials researchers across the globe, serving the strong community represented by MRS. You will hear more about this new section and how you might contribute to it in the coming months.

As we continue to move forward with an evolving Bulletin, we need your support to make this a better and, dare we say, a more impactful publication! We also need your input and feedback. Let us know your ideas and thoughts on how we can make MRS Bulletin a more valuable resource for you and the materials community.

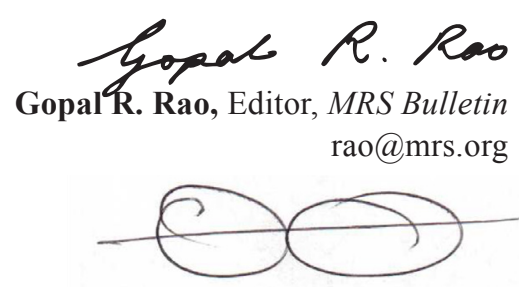

Markus J. Buehler, Impact Editor, MRS Bulletin mbuehler@mit.edu

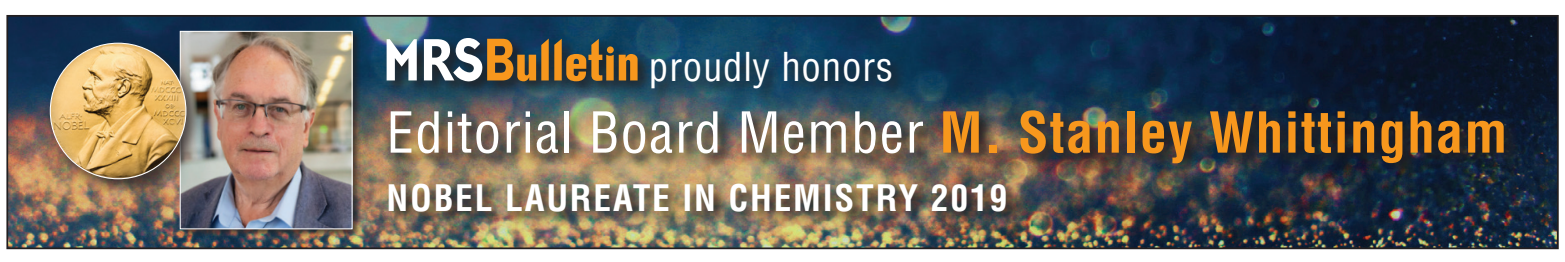

